\title{
Relações paradigmáticas entre Arquivologia e Ciência da Informação: a vivência prática de um arquivo
}

\author{
Jorge Santa Anna \\ Universidade Federal de Minas Gerais - UFMG, Brasil
}

REVIEW

\begin{abstract}
Resumo
Objetivo. Tematiza as relações existentes entre Arquivologia e Ciência da Informação à luz dos paradigmas que sustentam ambas as áreas. Objetiva identificar os pontos paradigmáticos observados em um arquivo público, a partir dos paradigmas norteadores dessas ciências, conforme elucidados na literatura.

Método. Com esse propósito, realiza-se revisão de literatura acerca da temática, bem como estudo de caso em um arquivo da Administração Pública Estadual. Este estudo foi conduzido por meio da técnica de observação e entrevista ao gestor da unidade.

Resultados. Os resultados demonstraram que o arquivo público, embora venha se modernizando, incrementando em suas práticas algumas características dos paradigmas descritos pela Ciência da Informação, a grande maioria dos fazeres arquivísticos é sustentado pelos paradigmas oriundos da Arquivologia. Portanto, dos sete pontos paradigmáticos identificados, cinco são oriundos da Arquivologia que são: foco no documento; atenção à custódia; acervo histórico e institucional; produção de documentos secundários; e, pouca preocupação com o usuário. Dois paradigmas são viabilizados pela Ciência da Informação, a saber: preocupação com a recuperação da informação e forte tendência à informatização. Conclusões. Evidencia-se que a preocupação com o acervo, suporte e tratamento técnico são paradigmas das ciências documentárias, os quais estão em consonância com o paradigma físico existente na área da Ciência da Informação, o que deduz ser a Ciência da Informação uma evolução das ciências documentárias. Essa inferência remete ao desenvolvimento de estudos futuros, a fim de gerar conclusões mais científicas.
\end{abstract}

Palavras-chave

Arquivologia; Ciência da Informação; Informação Arquivística; Paradigmas

\section{Paradigmatic relations between Archival Science and Information Science: the practical living of an archive}

\begin{abstract}
Objective. Theoretical relations between Archival Science and Information Science are thematic in light of the paradigms that sustain both areas. It aims to identify the paradigms observed in a public archive, from the paradigms guiding these sciences, as elucidated in the literature.

Method. With this purpose, a review of the literature on the subject is carried out, as well as a case study in a file of the State Public Administration. This study was conducted using the observation technique and interviewed the unit manager.

Results. The results obtained demonstrate that the public archive, although it has been modernizing, increasing in its practices some characteristics of the paradigms described by the Information Science, the great majority of the archival works is supported by the paradigms originating from the Archival Science. Therefore, of the seven paradigms identified, five come from the Archival Science that are: focus on the document; attention to custody; historical and institutional collection; production of secondary documents; and, little concern with the user. Two paradigms are made possible by Information Science, namely: concern with information retrieval and the computerization process.

Conclusions. It is evidenced that the concern with the collection, support and technical treatment are paradigms of documentary sciences, which are in line with the physical paradigm existing in the area of Information Science, which deduces that Information Science is an evolution of documentary sciences. This inference refers to the development of future studies in order to generate more scientific conclusions.
\end{abstract}

Keywords

Archival; Archival Information; Information Science; Paradigms 


\section{Introdução}

Uma das características essenciais das sociedades humanas diz respeito à capacidade de transformação. $O$ homem atua de uma forma interventiva no meio em que vive, haja vista buscar condições mais adequadas e apropriadas a seu convívio. Assim, ao longo dos tempos, as sociedades vão se evoluindo, por meio da adesão a novas condições e tendências oriundas das descobertas e conquistas humanas.

Essa busca pelo desenvolvimento constitui o alicerce da sociedade, sendo que nas relações estabelecem-se padrões a serem seguidos por uma coletividade, o que facilita as interações e favorece a busca por objetivos similares. O estabelecimento de padrões que norteiam as atividades de um grupo específico é percebido, principalmente, no âmbito científico.

A ciência busca o conhecimento, o qual garante o desenvolvimento da sociedade. Por meio de diversas áreas do saber, grupos são formados e instituídos, de modo a viabilizar algum tipo de contribuição aos desafios impostos pelo meio natural quanto social. Essas áreas manifestam-se nas práticas sociais por meio das profissões, as quais são pautadas em fundamentos e princípios científicos suficientes para garantir legitimidade e reconhecimento nas intervenções realizadas.

A fim de se consolidarem como organismos legítimos e instituídos, bem como garantir melhorias no meio social, as profissões comungam dos mesmos valores, princípios, concepções e intenções. Para tanto, sustentam-se em padrões ou modelos devidamente aceitos e seguidos por um grupo específico, denominados de paradigmas.

Os paradigmas estão presentes em todas as áreas do conhecimento, por conseguinte, insere-se no meio profissional. Esses paradigmas são estabelecidos com base nas tendências e desejos requeridos pela sociedade, logo, observa-se que as profissões devem reformular seus paradigmas constantemente, de modo que possam sobreviver diante de contextos mutantes, sobretudo com as transformações da sociedade moderna, assim como apontou o estudo de Cunha (2006).

As práticas profissionais devem acompanhar o progresso científico gerado com as ciências nas quais estão vinculadas, de modo que a sociedade perceba as contribuições dessas práticas na resolução de problemas e obstáculos oriundos da vivência social. Assim, os paradigmas que sustentam as áreas, segundo a tese de Kuhn (2009), devem estar em constante dinamismo, que por sua vez, quaisquer mudanças nesses paradigmas devem ser refletidas nos fazeres profissionais, o que demonstra a necessidade constante de transformações no exercício profissional.

Com efeito, a instabilidade do mercado globalizado tem gerado mudanças em todos os segmentos sociais, principalmente com o desenvolvimento e uso das tecnologias de informação e comunicação, cujo reflexo desse uso tem viabilizado a explosão da informação. Nesse contexto, segundo Valentim (1995), todas as profissões assumem novos valores e reformulam seus paradigmas, sendo que as profissões da informação não devem fugir a essa regra, que, não se configura apenas como uma tendência, mas sim, uma obrigatoriedade.

As profissões que lidam com a informação - aqui consideradas como tais profissões, a Arquivologia, Biblioteconomia e Museologia, áreas inseridas em um universo maior denominado de Ciência da Informação, conforme nos ensina Smit (2000) - tendo ela como objeto de estudo, estão em constante processo de aprimoramento de suas práticas, em que a interdisciplinaridade, o uso de novas tecnologias e a redefinição no conceito de informação têm desencadeado mudanças na forma como as unidades e serviços de informação atuam na atual sociedade (OLIVEIRA, 2005).

A informação desvinculada de seu suporte acarreta outros problemas e interesses de estudo, em que novas práticas são demandadas a partir da análise dos fluxos e canais de comunicação envolvidos durante todo o ciclo informacional. Além disso, a informação adquire novas percepções, sendo considerada como coisa, como processo e como conhecimento, um insumo básico para determinar a tomada de decisões nos mais diferenciados contextos, sejam eles sociais, culturais, políticos e institucionais (RIBEIRO; SILVA, 2008).

Essa dinâmica atribuída à informação, segundo proferido pelos autores supracitados, representou uma reviravolta para as unidades de informação, sobretudo no que se refere à tomada de decisões em organizações 
das mais diferenciadas, o que determinou mudanças radicais à Arquivologia, em virtude da nova concepção atribuída aos arquivos.

A Arquivologia, segundo Santa Anna (2015), constitui uma das áreas que dialogam com a Ciência da Informação, sendo que as teorias e princípios propostos por essa grande área viabilizam reformulações nas práticas profissionais dos arquivistas. Segundo Araújo (2014), a Arquivologia insere-se no universo da Ciência da Informação, havendo grandes pontos de aproximação, no entanto, em ambas as áreas, observam-se diferenças entre os paradigmas que as sustentam.

Segundo Oliveira (2005), a Ciência da Informação é uma área em expansão que intervém em todas as etapas do ciclo informacional, desde sua produção até seu acesso e uso. Portanto, a Ciência da Informação surge como uma tentativa de permitir que a informação materializada em diversos documentos possa ser disseminada na sociedade, tendo em vista a geração de novos conhecimentos. Por isso, entende-se, segundo Borko (1968), que essa ciência se atrela, mais intensamente, com o uso da informação e a gestão dos fluxos e forças que permitem a tramitação dessa informação.

No entendimento de Araújo (2014), a Arquivologia está relacionada ao armazenamento de documentos em diversos suportes, como também insere-se no paradigma do acesso, ao viabilizar novas formas de processamento e distribuição da informação em diversos canais e mídias, sendo necessário atuar na gestão dos canais e fluxos de informação, haja vista garantir o acesso, seja para fins de memória, ou para fins institucionais, na tomada de decisões, ou ainda, para valorizar e permitir o enriquecimento cultural.

Araújo (2014) constatou as possibilidades de aproximação como também os limites de atuação de cada uma dessas áreas. Com efeito, conclui-se que as áreas estão em constante evolução, tendo os limites de atuação respeitados e, ao mesmo tempo, práticas profissionais são compartilhadas, proporcionando contribuições recíprocas.

A partir dessa relação e considerando a necessidade de mudanças das práticas profissionais com base na reformulação paradigmática, questiona-se: que paradigmas sustentam a gestão de um arquivo? Quais as contribuições dos paradigmas da Ciência da Informação e da Arquivologia na formulação de práticas profissionais de arquivistas? O arquivo tem adotado os paradigmas de quais dessas áreas?

Essa vertente de pesquisa torna-se necessária em virtude das transformações que ocorrem na sociedade, o que desperta o interesse de investigação nas unidades de informação. Estudo realizado por Vieira e Ardigo (2015) identificou os paradigmas da Biblioteconomia e da Ciência da Informação em uma biblioteca especializada, concluindo que a maioria dos paradigmas estabelecidos nesse ambiente é oriundo de fazeres técnicos propostos pela Biblioteconomia.

Sendo assim, este artigo versa sobre a relação entre Arquivologia e Ciência da Informação, cujo objetivo é identificar os pontos paradigmáticos observados em um arquivo público, a partir dos paradigmas que sustentam a Arquivologia e a Ciência da Informação elucidados na literatura. Para atingir esse objetivo, realiza-se revisão de literatura da área, bem como estudo de caso em um arquivo da Administração Pública Estadual.

\section{Revisão de literatura}

\subsection{Os paradigmas da Ciência da Informação elucidados pela literatura}

A Ciência da Informação tem suas origens a partir da Segunda Guerra Mundial, especificamente no ano de 1962, tendo em vista atender as necessidades instituídas no período pós-guerra, sobretudo no que se refere à competitividade estabelecida entre as nações, na tentativa de estabilizar a economia e eliminar os prejuízos oriundos com o grande conflito mundial (SIQUEIRA, 2012).

A disputa por hegemonia entre as superpotências mundiais, Estados Unidos e antiga União Soviética, período denominado de Guerra Fria, despertou a necessidade desses países investirem em altas tecnologias, no intuito de ampliar as possibilidades de comunicação desses países com o restante do mundo. É por meio dessa necessidade infocomunicacional que novos valores foram atribuídos à informação (SIQUEIRA, 2012). 
A partir de então a informação passou a ser o recurso primordial na obtenção de conhecimento e de poder, haja vista a capacidade desse recurso em provocar inovação. Percebeu-se a necessidade de investir em altas tecnologias, de modo que a produção de um país, por conseguinte, seu desenvolvimento social e econômico, não estava mais ligado à indústria, mas sim à capacidade de desenvolver sistemas informatizados, munidos de inteligência artificial, capazes de gerar e transmitir informações em proporções gigantescas, sem considerar os impedimentos tempo-espaciais (RUSSO, 2010).

Nesse contexto, a informação ganhou outra dimensão como ampliou o seu valor e reconhecimento na sociedade, como um recurso inovador, fato esse que despertou maior valorização nas unidades de informação, como investimento em tecnologias para subsidiar os trabalhos desenvolvidos em arquivos e bibliotecas (ORTEGA, 2004).

No entanto, segundo essa autora, os processos de trabalho realizados nesses ambientes não eram suficientes para atender as exigências, necessidades e perspectivas da sociedade. O trabalho desenvolvido nessas unidades, sobretudo nas bibliotecas, estava pautado em uma concepção muito tecnicista, centrada no documento e seu suporte, o que não permitia práticas voltadas à gestão da informação e sua tramitação em diversos canais e fluxos.

Sendo assim, uma nova ciência é proposta nesse contexto, ou seja, uma ciência que extravasa os procedimentos técnicos comumente realizados em bibliotecas. Uma ciência que acompanhe a informação em todo o seu ciclo de vida, desde sua produção, incluindo seu processamento e armazenamento, como, principalmente, sua disseminação, acesso e uso, contribuindo, dessa forma, para a geração de conhecimento (SARACEVIC, 1996).

Na visão de Araújo (2014, p. 111), a priori, a Ciência da Informação não tem preocupação com a custódia ou posse dos documentos, mas com "[...] a sua circulação e sua disseminação da maneira mais produtiva possível. Depois, o foco não propriamente nos documentos (registro físico), mas em seu conteúdo objetivo ou, dito de outro modo, na informação contida nos documentos".

Oliveira (2005) lembra que a grande diferença da Ciência da Informação está em sua ampla capacidade de entender a maneira como a informação é usada, o que não representa uma atividade fim das tradicionais unidades da informação. Ou seja, para essa autora, tal ciência define um escopo de atuação ainda não contemplado pelas ciências documentais, as quais se sustentam em paradigmas voltados ao tratamento do suporte documental e não na informação que nele está contida.

Borko (1968) enfatiza que a Ciência da Informação traz em seu bojo a prática da gestão, interferindo em todas as etapas necessárias para que a informação gere conhecimento. Assim, a Ciência da Informação está alicerçada no acesso e no uso da informação, tendo também a missão de estudar todas as propriedades e característica desse recurso, além das forças que governam o seu intenso e contínuo fluxo.

Sendo assim, constata-se que:

Nas últimas quatro décadas a Ciência da Informação apresentou contribuições que influenciaram o modo como a informação é manipulada na sociedade e pela tecnologia e também permitiu melhor compreensão para um rol de problemas, processos e estruturas associados ao conhecimento, à informação e ao comportamento humano frente à informação. A Ciência da Informação desenvolveu um corpo organizado de conhecimentos e competências profissionais ligados às questões informacionais. Os fatos demonstram a veracidade dessas conclusões (SARACEVIC, 1996, p. 60).

Observa-se que a Ciência da Informação, conforme apontado pelo autor acima mencionado, sustenta-se em práticas mais complexas, envolvendo além do tratamento documental, o entendimento acerca do comportamento do usuário quanto ao uso da informação, sua recuperação e manuseio para produção de conhecimento e de inovações. Assim, evidencia-se uma maior preocupação com os usuários ou sujeitos informacionais e o uso da informação no contexto social, o que a evidencia como uma área social, conforme expresso na obra de Araújo (2014, p. 122), ao mencionar que essa ciência 
(...) não nasceu como uma ciência tipicamente social, mas identificou-se ao longo dos anos com o escopo das ciências sociais à medida que se orientou para uma postura em que os sujeitos passaram a ser vistos como o principal ator e objetivos dos chamados sistemas de informação, e que métodos e conceitos das ciências humanas e sociais foram aplicados para o seu estudo (ARAÚJO, 2014, p. 122, grifo nosso).

Importante considerar que o foco está na geração de produtos e serviços em informação, independente da forma como são oferecidos. A informação é vista como um processo que se dinamiza em meio a fluxos que precisam ser gerenciados, tendo as tecnologias da informação importante papel nesse contexto.

Portanto, a Ciência da Informação, segundo Ortega (2004) e Siqueira (2012), consolidou-se a partir de três importantes fenômenos, que são: o crescimento da interdisciplinaridade, o desenvolvimento das tecnologias da informação e comunicação - notadamente com a gênese da disciplina recuperação da informação - e a expansão da documentação. Assim, segundo as referidas autoras, essas disciplinas exerceram e exercem importante contribuição para que os paradigmas da Ciência da Informação fossem instituídos, por conseguinte viabilizaram o crescimento e consolidação dessa ciência na sociedade pós-moderna.

Para Saracevic (1996), a Ciência da Informação possui fortes relações com as tecnologias da informação, sendo que o desenvolvimento dos atuais sistemas informatizados de recuperação da informação representa uma alternativa para que os fluxos de informação sejam mapeados, permitindo, dessa forma, um gerenciamento efetivo da informação, como também ampliaram-se as possibilidades de busca e recuperação da informação, considerando-se as avançadas estratégias, instrumentos e técnicas destinadas a esse propósito.

Com base nessas características e especificações da Ciência da Informação, entende-se, portanto, que essa ciência sustenta-se em três distintos paradigmas: físico, cognitivo e sociocultural, os quais viabilizam diversas abordagens para fomentar os estudos acerca dessa ciência como área do conhecimento, que são: abordagem tradicional, alternativa e sociocultural, o que demonstra, por meio dessas distintas abordagens, o aspecto interdisciplinar dessa ciência (CAPURRO, 2003).

Para o referido teórico o paradigma físico, o qual viabiliza a abordagem tradicional, é aquele em que a informação é estudada como um objeto tangível, o que evidencia a importância aferida ao suporte documental, manifestando-se, nesse paradigma, as técnicas, instrumentos e metodologias de tratamento, processamento e organização de documentos em acervos documentais.

O paradigma cognitivo, correspondente à abordagem alternativa, considera a informação como um insumo dinâmico, em constante movimento, ou seja, a informação é caracterizada não como coisa, mas como processo, o que demonstra sua utilização para diferentes finalidades. Nesse aspecto, considera-se a informação como um construto que viabiliza a produção de conhecimento, configurando-se diferentes fluxos e canais de informação (CAPURRO, 2003).

Por sua vez, o paradigma sociocultural, pautado na abordagem sociocultural, corresponde à informação como produtora de conhecimento, sendo que esse conhecimento não pode ser medido, uma vez que está armazenado nas pessoas, constituindo o que se denomina de conhecimento tácito, fruto de experiências, vivências e habilidades pessoais. Nessa concepção, considera-se a preocupação com questões cognitivas, abordando-se estudos e práticas profissionais no contexto do acesso à informação e o comportamento do usuário quanto ao uso dessa informação (CAPURRO, 2003).

Mesmo possuindo essas peculiaridades e paradigmas específicos, nota-se, segundo Araújo (2014), grandes possibilidades de aproximação com as áreas que comungam do mesmo objeto. Assim, a Ciência da Informação é uma área científica, com identidade e unidade na perspectiva epistemológica e que abrange componentes aplicados tais como a Biblioteconomia, a Arquivologia, a Gestão da Informação e os Sistemas Tecnológicos de Informação "(...) todas elas centradas sobre um mesmo objeto de estudo e de trabalho - a Informação -, contextualizado em diferentes ambiências e serviços” (ARAÚJO, 2010, p. 82, grifo nosso).

Especificamente, quanto à relação da Ciência da Informação com a Arquivologia, Santa Anna (2015) sinaliza a importância de se redefinir os paradigmas da Arquivologia, uma vez que, em muitos contextos de atuação 
profissional, percebe-se uma intervenção voltada, tão somente, para o armazenamento e custódia dos documentos, desconsiderando-se o valor que a informação arquivística poderia exercer.

Segundo esse autor, a Ciência da Informação pode ser melhor dialogada com a Arquivologia, no sentido de fomentar práticas profissionais mais abrangentes, considerando-se a dinamicidade provocada com a desvinculação da informação ao seu suporte. Com isso, os profissionais e as unidades arquivísticas inserem-se em um contexto de reconstrução dos produtos e serviços arquivísticos a serem oferecidos a seus usuários.

\subsection{Paradigmas da Arquivologia elucidados pela literatura}

A Arquivologia tem suas raízes a partir da importância conferida aos arquivos, principalmente após a Revolução Francesa, os quais passaram a ser considerados como centros de desenvolvimento social por serem unidades voltadas para a memória social e cultural de uma dada sociedade, o que caracteriza um aspecto historicista aos arquivos dessa época, tendo o Estado como principal agente na gestão dessas unidades (LOPES, 2000).

No entanto, essa constitui a abordagem tradicional da Arquivologia, uma vez que seu desenvolvimento é acentuado no decorrer do século XIX, através da elaboração de técnicas e instrumentos capazes de conferir tratamento técnico aos documentos custodiados nos arquivos públicos (RIBEIRO; SILVA, 2008).

Para Araújo (2010), um dos marcos decisivos da Arquivologia diz respeito à elaboração dos manuais para tratamento de acervos documentários, tendo em vista tornar os documentos sistematizados e propensos a serem recuperados. Para esse autor, com base em Silva (2008), são marcos decisivos a formalização do conceito de fundo (o princípio do respeito aos fundos, de Natalis de Wailly, de 1841) e o Handeigling voor het ordenen em beschrijven van Archieven (conhecido como o "Manual dos holandeses"), de 1898. Seguem-se outros manuais, como os de Jenkinson, publicado em 1922, e o de Casanova, publicado em 1928. Esse modelo privilegia a dimensão patrimonial de acervos custodiados para servirem à produção historiográfica.

Os documentos armazenados nos arquivos são caracterizados conforme a função a que se destinam dentro de um contexto específico. Nessa vertente, tem-se a obra de Schellenberg (1973), com sua ênfase no valor primário dos documentos. Assim, a Arquivologia é fundamentada em duas teorias, a que considera o arquivo sob uma perspectiva historicista e a que o considera como um centro de tratamento e distribuição de documentos para fomentar as atividades sociais, econômicas e políticas no Estado Moderno (ARAÚJO, 2010). Para esse autor, a Arquivologia, nesse enfoque, passa a conviver com duas tendências dicotômicas, sendo essa cisão superada apenas na década de 1980, com os trabalhos de autores como Couture, Gagnon-Arguin e Rousseau, ligados à Universidade de Montreal, que propõem a integração da gestão de documentos e da Arquivologia histórica de forma a se ter uma ciência que engloba todo o ciclo de vida dos documentos.

Assim, os documentos armazenados em arquivos são considerados como

(...) conjunto estruturado de representações mentais codificadas (símbolos significantes), socialmente contextualizadas e passíveis de serem registradas num qualquer suporte material (papel, filme, banda magnética, disco compacto, etc.) e, portanto, comunicadas de forma assíncrona e multidirecionada (SILVA; RIBEIRO, 2008, p. 37).

O conceito de arquivo está fundamentado no conceito de documento de arquivo, o qual possui especificidades. As características específicas desses documentos acabam por privilegiar o contexto de criação e uso do documento em detrimento ao suporte, ou à informação contida no documento. As especificidades dos documentos arquivísticos podem ser resumidas da seguinte forma: 1 - imparcialidade, tendo em vista a veracidade dos arquivos; 2 - autenticidade: os arquivos são gerados como verossímeis e confiáveis para quem os necessita para agir; 3 -naturalidade, em que os arquivos são criados e acumulados de forma natural; 4 organicidade, considerando que os documentos de arquivo acumulam-se natural, progressiva e continuamente (DURANTI, 1994).

As novas concepções atribuídas ao conceito e às funcionalidades dos arquivos e seus acervos provocam estudos mais aprofundados sob uma tendência crítica, haja vista o valor social, as relações de poder e a capacidade dos arquivos em negociar, contestar e confirmar essas relações. Esse fato provoca o nascimento de uma disciplina contextualizada e mais abrangente, que realiza procedimentos que vão além das unidades 
arquivísticas. Ou seja, consolida-se um campo de reflexões na tentativa de superar as visões positivistas calcadas em pressupostos de neutralidade e passividade (FONSECA, 2005).

As duas correntes que fundamentaram o nascimento da Arquivologia Moderna, qual seja, Arquivologia Tradicional e a Arquivologia Integrada, estão fundamentadas em paradigmas distintos, ou seja, observa-se o paradigma da memória social e cultural, atrelado ao paradigma da custódia, preservação e armazenamento documental, tal como visto pela abordagem historicista/tradicional. Já a abordagem integrada manifesta-se por meio da gestão dos fluxos em que a informação arquivística é conduzida, desde seu nascimento, até seu descarte ou guarda permanente (ROUSSEAU; COUTURE, 1998).

Assim, é importante considerar que a proposta defendida pela segunda vertente, ou seja, a Arquivologia Integrada, não refuta ou exclui a primeira, ao contrário, no decorrer do século XX, a Arquivologia veio se consolidando como disciplina e ciência, melhorando os processos de trabalho demandados em arquivos e centros de documentação (RIBEIRO; SILVA, 2008).

No entendimento de Azevedo Pinto (2016), assiste-se, na atualidade, uma ciência que viabiliza práticas profissionais diversificadas, tais como a gestão documental, a avaliação, seleção e eliminação de documentos, os problemas da acessibilidade e comunicabilidade dos mesmos, os efeitos do aparecimento de novos suportes, de novas formas de produção e circulação, a questão da relação documento/informação.

Ainda de acordo com a tese do autor supracitado, considera-se que, nos dias atuais, o conceito de documento, de arquivo, assim como os papéis atribuídos à Arquivologia tem sido revistos, sendo que essa área tem se manifestado como fortemente atrelada e sustentada por concepções oriundas da Ciência da Informação. Assim,

\footnotetext{
O conhecimento de um arquivo já não se esgota na aplicação de técnicas e procedimentos padronizados (ordenar, descrever a forma e o conteúdo dos documentos, instalá-los e cotá-los), ou na apresentação descritiva do inventário ou catálogo. A Arquivística apresenta-se como uma ciência da informação social que estuda os arquivos (sistemas de informação (semi)-fechados), quer na sua estruturação interna e dinâmica própria, quer na interacção com os outros sistemas correlativos que coexistem no contexto envolvente (SILVA apud AZEVEDO PINTO, 2016, p. 2, grifo nosso).
}

Delmas (2010) também relata o valor social da Arquivologia, enquanto disciplina que investiga e intervém nas questões sociais, o que fortalece as relações entre esse campo do conhecimento e a Ciência da Informação. No entendimento de Delmas (2010), é preciso entender o arquivo sob uma concepção mais abrangente, considerando diferentes funcionalidades a ele atribuídas. Desse modo, o arquivo pode ser utilizado para fins jurídicos, tendo em vista o aspecto probatório dos documentos; é utilizado para fins de gestão, uma vez que os documentos permitem o resgate sobre informações históricas; fins científicos, haja vista a possibilidade de se compreender determinadas realidades, por meio dos documentos; e, por fim, o arquivo também pode ter uma utilidade social, na medida em que os documentos propiciam a transmissão da memória.

Araújo (2014) corrobora com a ideia de aproximação entre Arquivologia e Ciência da Informação, no entanto, descreve alguns paradigmas que não são integralmente compartilhados entre as duas áreas. Segundo esse autor, a Arquivologia tem suas origens nas ideias de posse do documento e reconstituição dos patrimônios arquivísticos nacionais, sendo que o prestígio de uma nação ou reconhecimento está na valorização atribuída a seus arquivos.

Outro ponto paradigmático existente no âmbito da Arquivologia diz respeito ao tratamento do registro de cada momento da vida social e também com as tensões resultantes das constantes dinâmicas de manipulação e repressão de memória. Não se pode deixar de mencionar os questionamentos de Terry Cook, segundo Araújo (2014), a respeito da nova proposta para a Arquivologia em que a concepção de documento passa a ser entendida sob o viés da autoridade, da evidência e da verdade, assim como também apontou os estudos de Suzana Briet (1951).

Não resta dúvida de que a entrada na Sociedade da Informação e os reflexos desencadeados pela evolução tecnológica geraram modificações no modo de se pensar o arquivo, bem como ampliou os fazeres arquivísticos. Essas modificações são refletidas por Cook (2012), as quais dialogam, também, com as propostas advindas da Documentação, conforme expôs Otlet (1937), considerado como pai dessa disciplina. Assim, reflete-se que o documento não deve ser visto somente por suas características físicas, mas também por seu conteúdo, bem como a informação nele contida, a qual pode ser distribuída a inúmeros contextos e instâncias o que viabiliza um novo posicionamento e intervenção do arquivo e do profissional que o gerencia. 
Cook (2012) enfatiza uma nova atividade profissional, à medida que o objeto de trabalho do arquivista deixa de ser o documento para ser a informação e sua capacidade transformadora. Assim, segundo esse autor, uma profissão enraizada no Positivismo do século XIX, muito mais do que em estudos anteriores ligados à Diplomática, resultou em estratégias e metodologias que já não são viáveis num mundo pós-moderno e computadorizado. Desse modo, o autor destaca a intervenção do profissional no contexto da informação, atuando como mediador e propagador da informação, de modo que o arquivo se insira em um paradigma póscustodia, em que o acesso, disseminação e uso da informação sejam as bases sustentadoras do fazer arquivístico.

Essa teorização proposta por Cook (2012) enriquece a prática profissional, de modo a romper velhos paradigmas e estabelecer novos modelos, a fim de tornar a profissão mais reconhecida e valorizada. Portanto, de acordo com estudo pragmático realizado por Azevedo Filho,

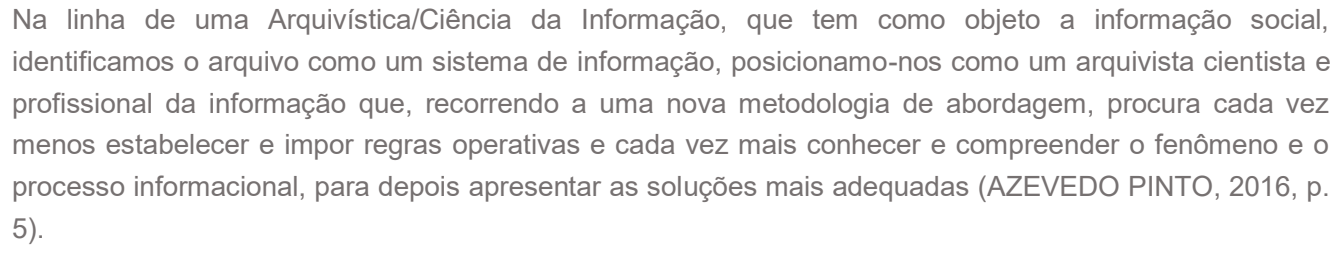

Cook (2012) salienta o papel do arquivo na sociedade, haja vista, permitir que o conhecimento seja gerado, o que viabiliza desenvolvimento pessoal e social. A participação dos arquivistas em projetos que viabilizem a cultura na sociedade, assim como o desenvolvimento de sistemas informatizados de gestão da informação no âmbito social, cultural e institucional, também constitui tendências emergentes no âmbito do pós-modernismo.

Nesse contexto, a Arquivologia, como área social, e por meio do estudo dos arquivos - ao considerar esses ambientes como interferentes no registro e guarda da memória e experiência humana - transfere-se de uma ciência documentária para uma ciência que garante a transparência das ações do Estado e das organizações e instituições existentes na sociedade (EASTWOOD; MACNEIL, 2016).

Essas práticas que extrapolam a custódia e o mero tratamento e gerenciamento documental são vistas como interferentes na reformulação de paradigmas e na consolidação de práticas inovadoras, segundo a pesquisa de Santa Anna (2015). Semelhante a esse autor, Azevedo Pinto (2016) defende que a Arquivologia na modernidade ampliou o seu campo de atuação, aproximando-o do campo da Ciência da Informação, fortalecendo as relações interdisciplinares de modo que, os arquivistas inserem-se em um paradigma dinâmico, voltado, sobremaneira, ao uso da informação, sendo necessária a aquisição de novas competências, habilidades e atribuições a esses profissionais.

A esse respeito, Araújo (2012), menciona a amplitude das funcionalidades dos arquivos, logo, novas técnicas e metodologias são estabelecidas, com o propósito de tratar os variados documentos arquivísticos. Esse tratamento condiciona uma concepção que privilegia o humano e social; portanto, faz-se necessário reformular as ações que sustentam o paradigma custodial/tecnicista.

Em grande parte, a reformulação paradigmática, em que pese o humano e social nas questões arquivísticas, é consequência do valor atribuída à informação contida nos documentos. Sendo assim,

\footnotetext{
(...) A partir do conceito de 'informação', poderia se potencializar reflexões que buscariam ir além do epifenômeno (os documentos, as materialidades custodiadas e processadas nas instituições) e produzir as compreensões no âmbito próprio das ações humanas (de produzir essas materialidades, selecioná-las entre outras, apropriar-se delas), o que nos reconduz para o estudo do universo da produção de sentidos e significados, os fluxos e movimentos dinâmicos, as interações e os contextos, as tensões entre o material e o imaterial [...] (ARAÚJO, 2012, p. 237).
}

No âmbito da Arquivologia, entender o que é e o que caracteriza a informação contida nos documentos de arquivo é de fundamental importância para estabelecer as tendências de atuação dos profissionais dessa área de conhecimento. Também é de extrema contribuição, considerar os princípios arquivísticos, que são: proveniência, unicidade, indivisibilidade, originalidade. O conhecimento desses princípios viabiliza uma gestão documental efetiva, por conseguinte, uma atuação profissional que contextualiza o documento, a informação que ele possui e o seu valor para a organização e sociedade (BELLOTO, 2007). 
No que tange à gestão de documentos, considera-se que ela representa o cerne das atividades arquivísticas e, portanto, norteia as atividades desenvolvidas pelos profissionais da área. Essa forma de gestão baseia-se em uma tríplice dimensão e ordem do objeto arquivístico, qual seja: arquivos-documentos de arquivo-informação (HEREDIA HERRERA, 1993).

Por meio do quadro 1, é posspivel identificar as fases em que a gestão de documentos deva ser conduzida, de modo a garantir uma prática profissional efetiva, com excelência e qualidade.

Quadro 1. Fases da gestão de documentos no âmbito da Arquivologia moderna

\begin{tabular}{|c|c|}
\hline Fase 1 & Estudo da tipologia documental, seu valor, vigência, classe e qualidade de sua informação \\
\hline Fase 2 & $\begin{array}{l}\text { Normalização de documentos para simplificação de etapas administrativas, inclusive as repetitivas, e de } \\
\text { formulários para remessa e estatísticas (investigação, empréstimos) }\end{array}$ \\
\hline Fase 3 & Informatização de processos de tramitação documental \\
\hline Fase 4 & Coordenação e colaboração entre organismos produtores e arquivo \\
\hline Fase 5 & $\begin{array}{l}\text { Regulamentação das transferências que possibilitam a reclamação dos produtores em caso de não se } \\
\text { fazerem as remessas nos prazos estabelecidos }\end{array}$ \\
\hline Fase 6 & $\begin{array}{l}\text { Estudo da classifi cação em cada caso, materializada na adoção de um quadro, resultado de um } \\
\text { organograma estabelecido }\end{array}$ \\
\hline Fase 7 & $\begin{array}{l}\text { Eleição da ordenação mais adequada, segundo as séries, nas organizações e em áreas de uma } \\
\text { informação mais efetiva e rápida }\end{array}$ \\
\hline Fase 8 & $\begin{array}{l}\text { Estudo dos descartes e suas listas, com o conseqüente estabelecimento de acordos para evitar a } \\
\text { remessa de séries descartáveis aos arquivos centrais }\end{array}$ \\
\hline Fase 9 & Incorporação de fundos e manutenção da informação atualizada \\
\hline Fase 10 & $\begin{array}{l}\text { Preparação de informações mediante a solicitação para o estudo de qualquer tema ou preparar qualquer } \\
\text { projeto }\end{array}$ \\
\hline Fase 11 & Elaboração de índices e de tesauros \\
\hline Fase 12 & Planejamento para informatização \\
\hline
\end{tabular}

Fonte: adaptado de Heredia Herrera (1993).

As 12 fases estabelecidas para concretização da gestão de documentos descritas por Heredia Herrera (1993) viabilizam a formação de diversas atividades a serem adotadas pelos profissionais, sobretudo quando a atuação profissional se manifesta no âmbito organizacional, conforme demonstrado por Valentim (2012).

Especificamente, no que tange à informação contida nos documentos, Valentim (2012, p. 12-13) defende que essa informação

\footnotetext{
(...) é compreendida de forma ampla, uma vez que congrega a informação orgânica (gerada internamente à organização) e a informação não orgânica (gerada externamente à organização). A informação arquivística é gerada em decorrência das transações estabelecidas entre a organização e seus stakeholders e é relacionada às funções, atividades e tarefas organizacionais.
}

Semelhante a Valentim (2012), a qual discorre sobre a informação arquivística como produto das atividades organizacionais, Tognoli (2012, p. 121, grifo nosso) também reforça a atenção que deve ser prestada pelo arquivista ao contéudo informacional materizado nos diversos suportes tecnológicos. Logo, a informação caracteriza-se em face do contexto em que é analisada, considerando os modos de produção, tratamento e gestão. Assim, segundo essa autora, o conceito de informação orgânica consegue tirar o documento do foco do arquivista, "(...) fazendo-o compreender que mais importante que o suporte, é a informação que ele carrega, e que esta informação é produzida em um contexto arquivístico". 
Valorizar a informação no contexto em que é produzida e direcionada para uso tende a promover novas formas de atuação do profissional que lida com essa informação, não estando ele apenas envolto às atividades de guarda e tratamento de acervos impressos, mas conferindo a esse profissional um perfil diferenciado e diversificado, sobretudo ao atuar como gestor da informação arquivística (TOGNOLI, 2012).

Com efeito, é possível perceber o quanto a prática arquivística deve ser reformulada de forma constante nas instituições e segmentos da sociedade que demandem por trabalho documental. Para tanto, segundo Sousa (2017), o paradigma que sustenta a prática profissional deve ser sustentado por um fazer pedagógico, atrelado aos seguintes aspectos: agir, pensar, refletir, inovar e, sobretudo, recriar. A partir desse fazer pedagógico é possível formar profissionais que modifiquem a realidade das instituições arquivísticas, de modo a questionar, inovar, inventar, melhorar, participar, arriscar, dentre outras ações que conduzam à melhoria dos processos empresariais e, por conseguinte, do rendimento organizacional.

\section{Metodologia}

Os procedimentos metodológicos que conduziram este estudo, tendo em vista o problema de pesquisa e o objetivo previamente formulado, foram a revisão de literatura e o estudo de caso. A primeira modalidade de pesquisa diz respeito à análise - por meio da leitura e resumos de textos bibliográficos devidamente publicados, tais como livros e artigos científicos - na literatura especializada a respeito dos temas paradigmas na Arquivologia e na Ciência da Informação. Já o estudo de caso constitui um tipo de investigação realizada em um ambiente específico, por meio de técnicas variadas, a fim de coletar dados sobre um fenômeno, processo, objeto ou atividade, considerando o contexto situacional.

Para realização da revisão de literatura, recorreu-se à busca de livros e artigos que versam sobre a temática, considerando como ambientes de busca, o acervo de uma biblioteca universitária, para os livros, e a base de dados Google Acadêmico para os artigos. De modo geral, após a recuperação dos artigos, a fim de depurar a amostra, realizou-se leitura prévia dos materiais recuperados, sendo que os que não se relacionavam com a temática foram devidamente descartados. Em linhas gerais, destacam-se como principais autores selecionados e utilizados na revisão, no caso dos livros: Araújo (2014), Oliveira (2005), Ribeiro e Silva (2008), Russo (2010) dentre outros. Para os artigos, destacam-se como principais teóricos: Araújo (2010), Azevedo Pinto (2016), Cook (2012), Ortega (2004), Santa Anna (2015), Siqueira (2012), dentre outros.

O ambiente in loco que sustentou o estudo de caso foi um arquivo público estadual. O objetivo principal dessa instituição é fomentar os documentos públicos produzidos pela sociedade em que a organização está inserida, garantindo, desse modo, para a consolidação da cidadania. As funções organizacionais se resumem à organização, guarda, preservação, recuperação e uso dos documentos inseridos no acervo arquivístico.

O referido arquivo possui um total de quinze colaboradores, os quais estão distribuídos nas seções de gestão do arquivo, tratamento documental e setor de informática. Essas seções estão subordinadas à direção geral, a qual possui um total de três arquivistas e cinco auxiliares. Historicamente, o arquivo foi instituído no ano de 1910, sendo seu acervo formado por documentos históricos relacionados à formação do Estado, como também documentos relativos aos primeiros habilitantes da região. Embora nas primeiras décadas, o acervo documental estava acoplado ao acervo da Biblioteca Pública, alguns anos posteriores, o arquivo adquire sua própria sede, além de ir reformulando as práticas arquivísticas, e se modernizando, sobretudo no que tange à incorporação de tecnologias digitais.

Ainda no estudo de caso, importante mencionar que foi utilizada a observação, como técnica ou instrumento de pesquisa, sendo realizadas no local, três visitas consecutivas. A observação foi conduzida por meio de um roteiro contendo em forma de tópicos os principais paradigmas da Ciência da Informação e da Arquivologia. Para cada tópico, anotava-se se havia ou não manifestação de cada paradigma nas práticas arquivísticas realizadas na referida unidade de informação. Além da observação, a fim de proporcionar esclarecimentos quanto às dúvidas geradas na observação, no último dia de visita, realizou-se uma entrevista com o arquivista da unidade, sendo realizadas perguntas abertas.

Após coleta dos dados, as informações adquiridas foram sistematizadas em um quadro, de modo que fosse possível visualizar a identificação do paradigma na realidade estudada. Além dessa identificação, procedeu-se às discussões acerca das informações coletadas com demais resultados de pesquisas contemplados na literatura da área de Arquivologia e Ciência da Informação. 


\section{Resultados e discussão}

Por meio das observações e entrevista realizadas no contexto de um arquivo público, foi possível identificar, através das práticas arquivísticas realizadas, alguns pontos que constatam a concretização de alguns paradigmas pertencentes à Arquivologia quanto à Ciência da Informação, considerando os pontos paradigmáticos dessas áreas, discorridos na literatura consultada.

Os procedimentos metodológicos utilizados estão de acordo com a recomendação de pesquisa proposta por Vieira e Ardigo (2015), ao realizarem estudo de caso em uma biblioteca especializada de uma instituição educacional, em que foram identificados mais pontos paradigmáticos pertencentes à Biblioteconomia do que à Ciência da Informação. Os autores sugeriram a realização de outros estudos de caso, tendo em vista a análise a diferentes unidades de informação.

Os pontos paradigmáticos pertencentes à Ciência da Informação descritos neste artigo foram elaborados, conforme as discussões propostas por autores que pesquisam acerca desse tema ou sobre assuntos relacionados a esse tema. Citam-se como principais autores mencionados na revisão de literatura: Borko (1968), Valentim (1995), Capurro (2003), Ortega (2004), Oliveira (2005), Russo (2010), Araújo (2010, 2012, 2014), dentre outros. Quanto aos pontos paradigmáticos da Arquivologia, consideram-se como principais autores estudados para formulação desses pontos: Briet (1951), Jardim (1992), Heredia Herrera (1993), Fonseca (2005), Belloto (2007), Delmas (2010), Cook (2012), Valentim (2012), Araújo (2014), dentre outros.

O quadro 2, a seguir, demonstra o ponto paradigmático identificado, a área a qual pertence cada um dos pontos, bem como as atividades realizadas que justificam essa identificação.

Quadro 2. Identificação dos pontos paradigmáticos nas atividades arquivísticas e sua relação com as áreas da Arquivologia e Ciência da Informação

\begin{tabular}{|c|c|c|c|}
\hline Ponto paradigmático & $\begin{array}{l}\text { Área a qual } \\
\text { o } \\
\text { paradigma } \\
\text { está } \\
\text { contido } \\
\end{array}$ & Justificativa & $\begin{array}{c}\text { Principais atividades realizadas ou } \\
\text { demais evidências }\end{array}$ \\
\hline $\begin{array}{l}\text { Foco no documento e } \\
\text { suas características } \\
\text { físicas do que na } \\
\text { informação nele } \\
\text { contida }\end{array}$ & Arquivologia & $\begin{array}{l}\text { A unidade possui como principal objetivo } \\
\text { o tratamento técnico dos documentos. }\end{array}$ & $\begin{array}{l}\text { Classificação, indexação, descrição e } \\
\text { arranjo de documentos }\end{array}$ \\
\hline $\begin{array}{l}\text { Preocupação } \\
\text { acentuada com o } \\
\text { armazenamento ou } \\
\text { custódia documental }\end{array}$ & Arquivologia & $\begin{array}{l}\text { Sistematização do acervo impresso por } \\
\text { meio de caixas específicas. Reparos em } \\
\text { documentos danificados. }\end{array}$ & $\begin{array}{l}\text { Organização por ordem alfabética dos } \\
\text { documentos. Identificação nas caixas. } \\
\text { Serviço de higienização e pequenos } \\
\text { reparos. Gestão da tabela de } \\
\text { temporalidade. }\end{array}$ \\
\hline $\begin{array}{l}\text { Pouca preocupação } \\
\text { com os usuários }\end{array}$ & Arquivologia & $\begin{array}{l}\text { A maioria das atividades realizadas gira } \\
\text { em torno da gestão de documentos e do } \\
\text { acervo. A única atividade em prol do } \\
\text { usuário refere-se ao atendimento e } \\
\text { auxílio prestado aos usuários no } \\
\text { momento da busca dos documentos. } \\
\text { Total ausência de treinamentos, estudos } \\
\text { de usuários e de outros serviços } \\
\text { relacionados à humanização. }\end{array}$ & $\begin{array}{l}\text { Atendimento telefônico e presencial. } \\
\text { Visitas orientadas a historiadores e } \\
\text { pesquisadores. }\end{array}$ \\
\hline $\begin{array}{l}\text { Acervo formado por } \\
\text { documentos } \\
\text { institucionais e } \\
\text { históricos }\end{array}$ & Arquivologia & $\begin{array}{l}\text { O arquivo possui documentos oriundos } \\
\text { das atividades desenvolvidas pela } \\
\text { organização, como também documentos } \\
\text { referentes à história da empresa e da } \\
\text { cidade onde está inserida. }\end{array}$ & $\begin{array}{l}1 \text { - Documentos administrativos: atas, } \\
\text { relatórios, projetos, correspondências, } \\
\text { notas ficais etc; } 2-\text { Documentos } \\
\text { históricos: cartas, portarias, decretos, } \\
\text { ofícios, fotografias etc. }\end{array}$ \\
\hline $\begin{array}{l}\text { Melhoria da } \\
\text { recuperação da } \\
\text { informação }\end{array}$ & $\begin{array}{l}\text { Ciência da } \\
\text { Informação }\end{array}$ & $\begin{array}{l}\text { A gestão do acervo não está pautada, } \\
\text { tão somente, na organização e custódia } \\
\text { dos documentos, mas há uma forte } \\
\text { preocupação com a recuperação da } \\
\text { informação, sobretudo quanto ao } \\
\text { desenvolvimento de softwares } \\
\text { especializados para gerenciamento, } \\
\text { como também, a utilização de } \\
\text { vocabulários controlados para facilitar a } \\
\text { recuperação do item. }\end{array}$ & $\begin{array}{l}\text { Elaboração e manutenção constante do } \\
\text { banco de dados, do sítio institucional, } \\
\text { dos equipamentos tecnológicos, e das } \\
\text { linguagens documentárias. }\end{array}$ \\
\hline $\begin{array}{l}\text { Forte tendência à } \\
\text { informatização }\end{array}$ & $\begin{array}{l}\text { Ciência da } \\
\text { Informação }\end{array}$ & $\begin{array}{l}\text { Embora a preocupação maior esteja em } \\
\text { torno do acervo em papel, inúmeros } \\
\text { esforços e ações vêm sendo realizadas }\end{array}$ & $\begin{array}{l}\text { Digitalização de fotografias e demais } \\
\text { documentos antigos. Construção do } \\
\text { acervo digital. Ampliação das estratégias }\end{array}$ \\
\hline
\end{tabular}




\begin{tabular}{|c|c|c|c|}
\hline & & $\begin{array}{l}\text { para formação do acervo digital, de } \\
\text { acesso online, como também melhoria } \\
\text { dos sistemas informatizados que } \\
\text { mantêm esses acervos }\end{array}$ & $\begin{array}{l}\text { de busca ao documento no catálogo } \\
\text { eletrônico. }\end{array}$ \\
\hline $\begin{array}{l}\text { Produção de } \\
\text { documentos } \\
\text { secundários } \\
\text { (complementares) } \\
\text { para viabilizar o } \\
\text { tratamento dos } \\
\text { documentos primários }\end{array}$ & Arquivologia & $\begin{array}{l}\text { A elaboração de subprodutos que } \\
\text { auxiliem às atividades de tratamento e } \\
\text { localização dos itens incorporados ao } \\
\text { acervo. }\end{array}$ & $\begin{array}{l}\text { Elaboração da tabela de temporalidade. } \\
\text { Construção de manuais de serviço. }\end{array}$ \\
\hline
\end{tabular}

Fonte: dados da pesquisa (2016).

Por meio da análise ao quadro 2, constata-se, a priori, a realização de atividades específicas dos arquivos, estando essas atividades relacionadas com as concepções tradicionais que viabilizaram a formação e institucionalização da área arquivística na sociedade. Isso se justifica, principalmente, quando se discute acerca do objetivo principal ou foco das atividades realizadas, quais sejam: tratamento técnico de documentos impressos, considerando suas características físicas e de estética, conforme é realizado nos processos de classificação, indexação, descrição e arranjo de documentos. Identifica-se, nessas atividades e tendências, o paradigma técnico que sustenta a Arquivologia quanto a Biblioteconomia e Museologia, assim como defendeu Araújo (2014) e Oliveira (2005).

Identificou-se, também, como ponto paradigmático relacionado aos paradigmas da Arquivologia, a preocupação acentuada com o armazenamento ou custódia documental, sendo identificadas como principais atividades a organização por ordem alfabética dos documentos, a identificação nas caixas, o serviço de higienização e pequenos reparos, e, por fim, a gestão da tabela de temporalidade. A esse respeito, Ribeiro e Silva (2008) consideram que a Arquivologia, a princípio, apoia-se na construção de técnicas e métodos para organização de documentos, no entanto, deve-se viabilizar, também, sua preocupação com a informação contida nos suportes, o que provoca uma aproximação com a Ciência da Informação.

Ainda no âmbito do paradigma do armazenamento e custódia documental, é importante frisar que, mesmo que a ordem alfabética seja adotada para fins de organização dos documentos, grande parte da literatura considera importante respeitar o princípio da ordem original dos documentos, que, nem sempre é alfabética. Quanto à tabela de temporalidade, a literatura demonstra ser viável a elaboração do Plano de Classificação que estabelecerá todas as relações e subordinações documentais e definirá, segundo legislações específicas, a guarda ou descarte dos documentos, no caso de arquivos correntes. No caso de arquivos permanentes, considerando que não se pode descartar documentos, deve-se estabelecer o Quadro de Arranjo, em detrimento à Tabela de Temporalidade.

Nota-se, também, como ponto paradigmático, pouca preocupação com o usuário da informação. As poucas atividades que relacionam com o fator humano, pelo menos, de uma forma direta, dizem respeito ao atendimento telefônico e presencial, visitas orientadas a historiadores e pesquisadores. Para Araújo (2014), o usuário da informação constitui um dos principais elementos considerados pela Ciência da Informação, sendo que nas demais ciências documentárias, como na Arquivologia, Biblioteconomia e Museologia, embora novos paradigmas dimensionam essas áreas para uma tendência humanista, a preocupação maior está ligada à tradição, em que o foco das atenções está no documento e não no seu usuário. Estudar o usuário, assim como o comportamento informacional, representa uma forma de humanização, estando atrelada, no âmbito da Ciência da Informação, aos paradigmas cognitivo e sociocultural, o que afere a essa área, seu caráter social, conforme mencionado na pesquisa de Capurro (2003).

Novamente, percebeu-se evidência com os paradigmas da Arquivologia, os diferentes itens que compõem o acervo informacional, sendo esse formado por documentos institucionais e históricos. O estudo de Lopes (2000) descreve que os arquivos são entidades que devem representar as instituições a que estão ligadas, armazenando, segundo Briet (1951), documentos que viabilizem a pesquisa, a prova e confronto. Ribeiro e Silva (2008) consideram os arquivos modernos como sistemas semiabertos e que congregam documentos de variadas formas e com finalidades das mais específicas, sendo que o uso desses documentos e a informação neles contida representa uma expansão para o fazer arquivístico.

Notou-se haver incentivos de melhoria à recuperação da informação, sobretudo pelo intenso planejamento e engajamento da equipe multidisciplinar que está desenvolvendo um acervo informatizado, a ser gerenciado com 
o uso do Software Sophia. O arquivo possui uma equipe de três profissionais ligados à área de Tecnologia da Informação, que, em colaboração com o arquivista visa tornar o acervo cada vez mais habilitado à recuperação. A esse respeito, tem-se o estudo de Silva (2013), quando afirma que o levantamento dos tipos documentais, expressos nos instrumentos de busca, a elaboração de instrumentos para gestão dos documentos, assim como os processos de guarda e disseminação da informação, além de facilitar a compreensão do documento no momento da recuperação da informação, demonstra o refinamento da elaboração do trabalho, bem como do conhecimento adquirido mediante uma pesquisa sobre os documentos. A utilização das tecnologias da informação, principalmente, a preocupação com a recuperação documental constitui um ponto que se aproxima do paradigma da Ciência da Informação.

Diante dessas inovações quanto ao interesse por tecnologias avançadas, assim como a tentativa de digitalizar boa parte dos documentos impressos, visando sua preservação e acesso, percebe-se que essa forte tendência à informatização está sustentada em um paradigma mais próximo da Ciência da Informação, uma vez que essa ciência, segundo Saracevic (1996), caracteriza-se por sua forte interdisciplinaridade e relacionamento estabelecido com as tecnologias digitais. Assim, de acordo com as informações coletadas no estudo de caso, tem-se que o arquivo investe nessa empreitada, pois realiza digitalização de fotografias e demais documentos antigos; está em fase de construção do acervo digital, como também estuda projetos para ampliar as estratégias de busca ao documento no catálogo eletrônico. A esse respeito, desde a década de 1990, Jardim (1992) defende a ideia de que a informatização dos arquivos despertará um maior uso dessa instituição, uma vez que as redes eletrônicas desencadeiam novas formas de sociabilidade e facilitam a construção de canais infocomunicacionais, portanto, segundo esse autor, através dos arquivos informatizados, prevê-se uma nova geração de pesquisadores, familiarizada com aplicações informáticas, em que serão estabelecidas novas demandas de consulta por meio eletrônico aos arquivos.

O último ponto paradigmático identificado nesta pesquisa refere-se a uma das atividades básicas e tradicionais da Arquivologia, que, segundo Otlet (1937), contempla os novos produtos gerados a partir do tratamento técnico realizado em prol da organização dos acervos. Esses produtos são denominados por esse autor de "documentação secundária", tais como ficha de registros dos documentos, tabelas e manuais para armazenamento, resumos, resenhas etc., e constituem, segundo Ortega (2004), um dos principais fazeres realizados em unidades de informação que tentam organizar seus documentos por meio da sistematização de acervos. No âmbito da Arquivologia, essas tendências evidenciam a consolidação de um paradigma técnico e custodial, em que a preocupação tem sido conferida com maior intensidade, ao elemento físico, como nos ensinam Ribeiro e Silva (2008). As principais atividades que justificam a presença desse paradigma no arquivo aqui analisado são: elaboração da tabela de temporalidade e de manuais de serviço.

\section{Considerações finais}

Por meio desta pesquisa foi possível discorrer acerca dos principais paradigmas que sustentam a área da Arquivologia e da Ciência da Informação, e a identificação de pontos paradigmáticos presentes nas atividades que permeiam o cotidiano de trabalho de um arquivo público.

Em linhas gerais, de acordo com a literatura, a preocupação com o documento e suas características físicas, assim como as metodologias para sistematização, organização e armazenamento desses documentos em acervos constituem atividades arquivísticas por excelência, o que caracteriza a concretização de um paradigma técnico, físico e custodial. Por sua vez, a transferência de atenção do documento à informação nele contida, logo, o foco no usuário e suas necessidades, assim como o uso das tecnologias que viabilizem melhor sistematização dos acervos e da disseminação da informação através de redes eletrônicas evidencia o aperfeiçoamento do paradigma físico utilizado nas ciências documentárias, através de um paradigma cognitivo e sociocultural, pautado na interdisciplinaridade, na informatização e na humanização.

Por meio das técnicas de observação e entrevista in loco, constatou-se que o arquivo público, embora venha se modernizando, incrementando em suas práticas algumas características dos paradigmas descritos pela Ciência da Informação, a grande maioria dos fazeres arquivísticos são sustentados pelos paradigmas oriundos da Arquivologia. Portanto, dos sete pontos paradigmáticos identificados, cinco são oriundos da Arquivologia que são: foco no documento; atenção à custódia; acervo histórico e institucional; produção de documentos secundários; e, pouca preocupação com o usuário. Dois paradigmas são viabilizados pela Ciência da Informação, a saber: preocupação com a recuperação da informação e forte tendência à informatização. 
Esses resultados eram previsíveis e desejados, uma vez que a grande maioria das práticas arquivísticas é realizada nos arquivos. No entanto, o crescimento da Ciência da Informação deve representar uma contribuição para as ciências documentais, de modo que as unidades de informação da atualidade ampliassem as práticas realizadas, reformulando seus paradigmas, a partir das contribuições da Ciência da Informação, fato esse que tornaria a área e as unidades de informação cada dia mais adaptativas, inovadoras, reconhecidas e valorizadas na sociedade pós-moderna, como desejam, preconizam e vislumbram inúmeros teóricos da pós-modernidade.

Embora não tenha sido intenção imediata, o estudo também confirma forte aproximação da Arquivologia com a Ciência da Informação, sendo que os paradigmas dessa ciência estão sendo inseridos, constantemente, aos fazeres arquivísticos, colaborando, assim, para o crescimento e expansão da Arquivologia. Além disso, evidencia-se que a preocupação com o acervo, suporte e tratamento técnico são paradigmas das ciências documentárias, os quais estão em consonância com o paradigma físico existente na área da Ciência da Informação, o que deduz ser a Ciência da Informação uma evolução das ciências documentárias. Uma profunda discussão desse relacionamento entre paradigmas e a evolução da Ciência da Informação à luz das ciências documentárias viabilizam o desenvolvimento de estudos futuros.

\section{Referências}

ARAÚJO, Carlos Alberto Ávila. Ciência da Informação como campo integrador para as áreas de Biblioteconomia, Arquivologia e Museologia. Informação e Informação, Londrina, v. 15, n. 1, p. 173-189, jul./dez. 2010. Disponível em: <http://www.uel.br/revistas/uel/index.php/informacao/article/view/4744>. Acesso em: 1 maio 2016.

Potencialidades do Diálogo entre a Arquivologia, a Biblioteconomia, a Museologia e a Ciência da Informação. In: VALENTIM, Marta Lígia Pomin (Org.). Estudos avançados em Arquivologia. Marília: Oficina Universitária; São Paulo: Cultura Acadêmica, 2012. p. 217-242. 2014.

. Arquivologia, Biblioteconomia, Museologia e Ciência da Informação: o diálogo possível. Brasília: Briquet de Lemos,

AZEVEDO PINTO, Maria Manuela Gomes de. O novo paradigma da arquivística: um estudo de caso. 2016. Disponível em: <http://ler.letras.up.pt/uploads/ficheiros/3090.pdf>. Acesso em: 5 maio 2016.

BELLOTO, Heloisa Liberalli. Arquivos Permanentes: tratamento documental. São Paulo: FGV, 2007.

BORKO, Harold. Information science: what is it? American Documentation, v. 19, n. 1, p. 3-5, 1968.

BRIET, Suzanne. What is Documentation? 1951. Disponível em: <http://ella.slis.indiana.edu/ roday/what>. Acesso em: 5 maio 2016.

CAPURRO, Rafael. Epistemologia e ciência da informação. In: ENCONTRO NACIONAL DE PESQUISA EM CIÊNCIA DA INFORMAÇÃO, 5., 2003, Belo Horizonte. Anais... Belo Horizonte: Associação Nacional de Pesquisa e Pós-Graduação em Ciência da Informação e Biblioteconomia, 2003.

COOK, Terry. Arquivologia e Pós-modernismo: novas formulações para velhos conceitos. Informação Arquivística, Rio de Janeiro, v. 1, n. 1, p. 123-148, jul./dez. 2012. Disponível em: <http://www. aaerj.org.br/ojs/index.php/informacaoarquivistica/article/view/9/20>. Acesso em: 5 maio 2016.

CUNHA, Mirian Vieira da. As profissões e as suas transformações na sociedade. In: SOUZA; Francisco das Chagas de (Org.). Comunicação, gestão e profissão: abordagens para o estudo da Ciência da Informação. Belo Horizonte: Autêntica, 2006, p. 141-150.

DELMAS, Bruno. Arquivos para quê? Textos escolhidos. São Paulo: Instituto Fernando Henrique Cardoso, 2010.

DURANTI, Luciana. The concept of appraisal and archival theory. The american archivist, Chicago, v. 57, n. 2, p. 328-344, 1994.

EASTWOOD, Terry; MACNEIL, Heather. Correntes atuais do pensamento arquivístico. Belo Horizonte: UFMG, 2016.

FONSECA, Maria Odília. Arquivologia e ciência da informação. Rio de Janeiro: Ed. FGV, 2005.

HEREDIA HERRERA, Antônia. Archivística general stica general: teoría y práctica. Sevilla: Disputacíon de Sevilla, 1993.

JARDIM, José Maria. As novas tecnologias da informação e o futuro dos arquivos. Estudos Históricos, Rio de Janeiro, v. 5, n. 10, p. 251-260, 1992. Disponível em: <http://www.uel.br/pessoal/jneto/arqtxt/novastecnologiasJNETO.pdf>. Acesso em: 9 maio 2016. 
KUHN, Thomas. A estrutura das revoluções científicas. 9. ed. São Paulo: Perspectivas, 2009.

LOPES, Luiz Carlos. A nova arquivística na modernização administrativa. Rio de Janeiro: Papéis e Sistemas, 2000.

OLIVEIRA, Marlene de (Coord.). Ciência da Informação e Biblioteconomia: novos conteúdos e espaços de atuação. Belo Horizonte: Ed. UFMG, 2005.

ORTEGA, Cristina Dotta. Relações históricas entre Biblioteconomia, Documentação e Ciência da Informação. DataGramaZero, Rio de Janeiro, v. 5, n. 5, out. 2004. Disponível em: $<$ http://www.brapci.ufpr.br/documento.php?dd0=0000002048\&dd1=05069>. Acesso em: 15 mar. 2016.

OTLET, Paul. Documentos e documentação: introdução aos trabalhos do Congresso Mundial da Documentação Universal. Paris, 1937. Disponível em: <http://www.conexaorio.com/biti/>. Acesso em: 5 maio 2016.

RIBEIRO, Fernanda; SILVA, Armando Malheiros de. Arquivística: teoria e prática de uma ciência da informação. 3. ed. Porto: Afrontamento, 2008

ROUSSEAU, Jean-Yves; COUTURE, Carol. Os fundamentos da disciplina arquivística. Lisboa: Dom Quixote, 1998.

RUSSO, Marisa. Fundamentos de Biblioteconomia e Ciência da Informação. Rio de Janeiro: E-papers, 2010.

SANTA ANNA, Jorge. A Arquivística no universo da Ciência da Informação: práticas profissionais em (re)construção. Biblionline, João Pessoa, v. 11, n. 2, p. 5-18, 2015. Disponível em: <http://periodicos.ufpb.br/ojs2/index.php/biblio/article/view/25204/15175>. Acesso em: 5 maio 2016.

SARACEVIC, Tefko. Ciência da informação: origem, evolução e relações. Perspectiva em Ciência da Informação, Belo Horizonte, v. 1, n. 1, p. 41-62, jan./jun. 1996. Disponível em: <http://www.brapci.inf.br/index.php/article/view/0000003224/571b9745e73c9913e24c21997c5a4cdc/>. Acesso em: 17 mar. 2016 .

SCHELLENBERG, Theodore Roosevelt. Arquivos modernos: princípios e técnicas. 2. ed. Rio de Janeiro: Ed. Fundação Getúlio Vargas, 1973.

SILVA, Marina Selina Soares. Configuração e recuperação da informação em documentos de ciência e tecnologia: estudo tipológico em arquivo pessoal no arquivo pessoal do físico Bernhard Gross. Perspectivas em Ciência da Informação, Belo Horizonte, v. 18, n. 3, p. 160-174, jul./set. 2013. Disponível em: <http://www.scielo.br/pdf/pci/v18n3/11.pdf>. Acesso em: 9 maio 2016

SIQUEIRA, Jessica Camara. Ciência da Informação: personagem da pós-modernidade. Revista Brasileira de Biblioteconomia e Documentação, São Paulo, v. 8, n. 1, p. 14-33, jan./jul. 2012. Disponível em: <http://rbbd.febab.org.br/rbbd/article/view/186/217>. Acesso em: 28 mar. 2016.

SMIT, Johanna. O profissional da informação e sua relação com as áreas de Biblioteconomia/Documentação, Arquivologia e Museologia. In: VALENTIM, Marta Lígia (Org.). Profissionais da informação: formação, perfil e atuação profissional. São Paulo: Polis, 2000

SOUZA, Renato Tarciso Barbosa de. Os desafios da formação do arquivista no Brasil. 2017. Disponível em: <http://www.aag.org.br/anaisxvcba/conteudo/resumos/plenaria2/renatotarciso.pdf>. Acesso em: 15 dez. 2017.

TOGNOLI, Natália. A informação no contexto arquivístico: uma discussão a partir dos conceitos de informação-como-coisa e informação orgânica. Informação Arquivística, Rio de Janeiro, v. 1, n. 1, p. 113-122, jul./dez. 2012. Disponível em: <http://www.aaerj.org.br/ojs/index.php/informacaoarquivistica/article/view/8/7>. Acesso em: 15 jan. 2018.

VALENTIM, Marta Lígia Pomim. Assumindo um novo paradigma na Biblioteconomia. Informação \& Informação, Londrina, p. 2 6, jul./dez. 1995.

Gestão documental em ambientes empresariais. In: Oficina Universitária; São Paulo: Cultura Acadêmica, 2012. p. 11-26.

(Org.). Estudos avançados em Arquivologia. Marília:

VIEIRA, Diego de Castro; ARDIGO, Julibio David. Paradigmas da biblioteconomia e ciência da informação: estudo de caso em uma unidade de informação especializada. Revista ACB, Florianópolis, v. 20, n. 1, p. 124-137, jan./abr. 2015. Disponível em: <https://revista.acbsc.org.br/racb/article/view/993>. Acesso em: 10 jan. 2017 


\section{Dados do autor}

\section{Jorge Santa Anna}

Graduado em Biblioteconomia. Mestrando do Programa de Pós-Graduação em Gestão e Organização do conhecimento, da Universidade Federal de Minas Gerais (UFMG). Atua no ramo da consultoria em informação científica.

jorjao20@yahoo.com.br

Recebido - Received: 2017-09-21

Aceitado - Accepted: 2018-01-26

\section{$(\mathrm{cc})$ EY}

This work is licensed under a Creative Commons Attribution 4.0

United States License.

\section{ULIS DDofe}

This journal is published by the University Library System of the University of Pittsburgh as part of its D-Scribe Digital Publishing Program and is cosponsored by the University of Pittsburgh Press. 